\title{
Individuação e Informação em Gilbert Simondon
}

\section{Individuation and Information in Gilbert Simondon}

\begin{abstract}
Resumo:
Nesse artigo a teoria da individuação de Gilbert Simondon é apresentada como uma das estratégias de superação da visão substancialista que, ao longo dos séculos, tem concebido os seres como formas estáveis e idênticas a si próprias, menosprezando o processo, o devir, a diferença, a irreversibilidade temporal. Tomando como eixo de análise os conceitos de informação, individuação, metaestabilidade, transdução e intensidade, em uma articulação e com conceitos de autores como Deleuze, Guattari, Prigogine, Stengers, Serres e Bydens, problematiza-se algumas teorias que sustentam a supremacia da Forma, da substância e dos seres individuados e propõe-se uma abordagem ontogenética na qual privilegia-se 0 processo de engendramento dos seres.
\end{abstract}

Palavras-chave: Individuação. Informação. Intensidade. Simondon. Deleuze-Guattari.

\begin{abstract}
:
In this article, the theory of Gilbert Simondon's individuation is presented as one of the strategies for overcoming of a substantialist view, that over the centuries has developed beings as stable forms and identical to themselves, disregarding the process, the becoming, difference, irreversibility of time. Taking as a point of analysis the concepts of information, individuation, metastability, transduction and intensity as developed by Simondon, in conjunction with concepts of other authors as Deleuze, Guattari, Prigogine, Stengers, Serres and Bydens, this article questions some theories that support the supremacy of form, substance and of individual beings, proposing an ontogenetic view on which privileges the process of engendering beings - the process of individuation.

Keywords: Individuation. Information. Intensity. Simon-
\end{abstract} don. Deleuze-Guattari.

ESCÓSSIA, Liliana da. Individuação e informação em Gilbert Simondon. Informática na Educação: teoria \& prática, Porto Alegre, v. 15, n. 1, p. 19-30, jan./jun. 2012.

\author{
Liliana da Escóssia \\ Universidade Federal de Sergipe
}

\section{Introdução}

D iversas teorias, ao abordaram o ser físico, biológico, psíquico ou social, como formas estáveis e idênticas a si próprias, foram unânimes em calar, negar ou contornar os processos, o devir, a diferença, a irreversibilidade temporal. Esta é uma afirmação presente nas análises de alguns pensadores como Gilles Deleuze, Félix Guattari, Ilya Prigogine, Isabelle Stengers, e, especialmente, Gilbert Simondon. Constitui-se, de certa maneira, como um problema a ser enfrentado, de maneira singular, por cada um deles, em uma rede conceitual que possui em comum o privilégio concedido ao processo, à relação - lugar-meio de sentido -, da qual emergem, simultaneamente, sujeito e objeto, forma e matéria.

Nesse artigo tomaremos a teoria da individuação, desenvolvida por G. Simondon, como uma das estratégias de aproximação e superação do problema esboçado acima, tendo como eixo de análise a problematização que o autor realiza sobre a noção de forma e sobre a relação entre forma e matéria, em suas versões platônica e aristotélica - bem como seus desdobramentos em outros sistemas te- 
óricos, como a Psicologia da Forma e a Teoria da Informação. São concepções assentadas em duas maneiras opostas de conceber essa relação, mas partem, ambas, de uma mesma afirmação sobre a supremacia da forma/ substância e de uma valorização do seres individuados, em detrimento do processo que os engendra, que os constitui - o processo de individuação. Partilham, portanto, de uma lógica substancialista reproduzida incessantemente ao longo dos séculos, gerando oposições e hierarquias na concepção dos seres e da realidade. Imanente ou transcendente, anterior ou contemporânea à operação de tomada de forma, a Forma, graças a uma suposta unidade, totalidade e coerência essencial, conserva sua superioridade com relação à matéria, configurando uma oposição entre dois tipos de realidade - aquela que recebe a Forma e aquela que a encerra.

Recusando a formulação acima por considerá-la insuficiente para dar conta de um plano processual dos seres, Simondon (1964, 1989) desenvolve uma concepção na qual a noção de forma é inserida numa rede conceitual que comporta noções como metaestabilidade, transdução, campo de intensidade, energia potencial e, informação. Em tal concepção, a forma é pensada não como princípio de individuação, que age de cima ou do exterior, mas como informação. Esta, por sua vez, deixa de ser uma grandeza absoluta e quantificável e de ter o sentido que lhe era atribuído tradicionalmente pela tecnologia das transmissões de mensagens - informação como aquilo que circula entre emissor e receptor - para ser pensada como troca significativa e irreversível, como a própria operação transdutiva de tomada de forma que caracteriza todo processo de individuação, processo através do qual se dá a emergência dos indivíduos a partir de um fundo pré-individual, operando uma defasagem do ser em indivíduo e meio.
Em trabalhos anteriores (ESCOSSIA, 1999, 2010), onde abordamos a temática da invenção técnica, essa noção de informação como operação de tomada de forma foi decisiva para sairmos de uma visão psicologizante da invenção. A invenção foi definida como resultado de uma relação transindividual ${ }^{1}$, efeito de agenciamentos coletivos entre homem e matéria, homem e mundo. Em tal abordagem o objeto técnico adquire dois estatutos: o primeiro é o de ser suporte e símbolo da relação transindividual, uma vez que traz consigo algo do ser que o inventou, uma natureza humana anterior, porém, à humanidade constituída no homem. Ao inventar, todo homem emprega seu apeiron ${ }^{2}$, uma dimensão préindividual e coletiva que embora ligado a cada ser individual, não Ihe pertence. 0 segundo estatuto, destacado tanto por Simondon (1989) quanto por Michel Serres (1993), é o de portador e mensageiro de informação e sentido. Isso implica em uma formulação anterior relativa à noção de matéria: a de que a matéria informa, não só porque transmite e veicula informação, mas porque a forma está presente na própria matéria e decorre de sua tecnicida$\mathrm{de}^{3}$, ou seja, de suas propriedades, da natureza de seus elementos (como a propriedade singular de ligação e conexão dos átomos do silício, por exemplo). Resulta que todo ato de invenção deixa de ser algo abstrato, operação intelectual do homem ou formatação da matéria pelo espírito/forma, para ser inserido em um regime de virtualidades da própria matéria, entendido como o que há de mais concreto, e como relação de agenciamento, acoplamento ou composição entre duas formas.

1 Relação transindividual é aquela que ocorre entre realidades pré-individuais e coletivas e não entre indivíduos constituídos (SIMONDON, 1989).

2 Palavra grega que designa o caráter indeterminado e infinito da natureza, em constante movimento.

3 Tecnicidade: conceito forjado por Simondon (1958) para falar do aspecto de concretude das virtualidades da matéria. 


\section{Da forma às forças}

A noção de individuação é o fio condutor do pensamento de Simondon. Através dela, o autor desenvolve uma abordagem ontogenética ${ }^{4}$, na qual importa "conhecer o indivíduo através da individuação e não a individuação a partir do indivíduo" (SIMONDON, 1989, p. 12). Com isso ele recusa, a um só tempo, o monismo substancialista de Platão - que considera o ser como unidade fundada sobre si mesma e o dualismo do esquema hilemórfico aristotélico - segundo o qual o ser é engendrado pelo encontro de uma forma com uma matéria.

Há, segundo o autor, uma oposição significativa e complementar entre a forma arquetípica de Platão e a forma hilemórfica de Aristóteles. A primeira, baseada na operação de cunhar moedas através da impressão de uma primeira peça original, é o modelo de tudo que é superior, eterno e único. A relação entre o arquétipo e as cópias define o primeiro modo vertical de interação. Uma interação não recíproca e assimétrica, já que o arquétipo é superior e anterior à peça, não tendo necessidade da mesma para existir. Nesse modelo platônico, as cópias podem sofrer degradação mas a forma/idéia é imutável: não se degrada nem progride, sua perfeição está dada na origem, em um mundo eterno e transcendente. A degradação caracteriza apenas o que é engendrado, ou seja, a cópia ou o ser sensível.

Tal como apresentada por Platão, perfeita desde a origem, superior e imutável, a forma fornece as bases para diversas teorias psicológicas e sociológicas nas quais a permanência, a fixidez e a estabilidade se constituem como ideais. Subjetividades, grupos, instituições e sociedades ideais são aquelas dotadas de uma inércia que as tornam relativamente

4 Para um maior aprofundamento sobre a abordagem ontogenética, ver Escóssia (1999). permanentes, estáveis e imutáveis, graças às leis invariantes que as governam, tal como é suposto acontecer na física. Simondon afirma que embora Platão tenha procurado, ao final de sua vida, encontrar uma fórmula capaz de explicar o devir - através da noção de idéiasnúmeros, ou de díade-indefinida - o essencial de sua doutrina é a forma arquetípica, entendida como estrutura anterior e superior a todos os seres engendrados.

Ao contrário, a forma hilemórfica de Aristóteles encontra-se no interior do ser individual e intervém no jogo de interação entre estrutura e matéria. Não é estritamente eterna nem imutável como a forma platônica, já que passa da virtualidade à atualidade no interior do próprio indivíduo, indicando certa relação entre a forma e matéria, uma relação de natureza inferior, que depende do ser individual para existir. Este, por sua vez, tende à forma. Esta idéia de tendência em Aristóteles é concebida a partir de uma visão animista do mundo, segundo a qual todo objeto tenderia para a perfeição, para a forma ideal, realização de sua perfeita natureza, em função da classe ao qual pertence. A classe determina o ser e sua finalidade. Embora decorrente de uma relação, de um processo de interação, o devir aristotélico, segundo Simondon (1989), é um devir finalista, pois a interação é própria do ser, ainda que pressuponha um certo grau de reciprocidade entre forma e matéria. Assim como em Platão, há em Aristóteles uma superioridade da forma, o que muda é que a forma hilemórfica se atualiza no ser individual, sendo contemporânea à tomada de forma, ao contrário da forma platônica, que é anterior. Mas o ser individual aristotélico permanece primeiro e superior à interação, o que define uma hierarquia característica das relações verticais.

Platão, com a forma eterna, recorre a um motor, um poder, que não é outro senão o Bem, o qual ilumina o mundo das idéias projetando 
sua sombra sob a forma de sensíveis. Aristóteles afirma um devir na interação formamatéria, mas este é apresentado como uma tendência natural: uma criança cresce porque tende em direção ao adulto, uma glande de carvalho tende a se transformar num carvalho adulto, etc. Ou seja, as interações ocorrem no interior do próprio ser individual, este é primeiro e por isso encerra poder do devir. Como afirmam Simondon (1989), são duas maneiras distintas de conceber a relação entre forma e matéria, mas que partem igualmente de uma idéia de supremacia da forma e da substância, idéia que nem a Idade Média nem o Renascimento, conseguiram reverter, através de uma possível uma articulação entre a forma arquetípica e a forma hilemórfica que resultasse num novo modo de conceber essa relação. Simondon considera que Giordano Bruno foi um dos que tentou realizar uma síntese entre o nível individual e grupal do ser, entre o elemento e o todo, não obtendo êxito justamente porque Ihe faltava a chave para a análise dos processos de interação - a noção de campo.

A noção de campo aparece na segunda metade do século XIX, nos trabalhos desenvolvidos pelos físicos Michael Faraday e James Ckerk Maxwell, marcando uma ruptura com a visão de mundo da mecânica clássica. Segundo o modelo newtoniano da física, a realidade era formada de corpos materiais que poderiam ser divididos infinitamente, agindo uns sobre os outros por gravitação. Os trabalhos de Faraday, no campo da eletricidade, sugeriam uma forte ação do meio, posteriormente comprovada matematicamente por Maxwell. Decorre disto uma concepção eletromagnética da luz e com ela a noção de campo eletromagnético, no qual as forças se propagam. A noção de campo se refere não a uma adição de elementos, mas a uma dinâmica de forças e "estabelece uma reciprocidade de status ontológico e de modalidades operatórias entre o todo e o elemento" (SIMONDON, 1989, p. 44). Em todo campo, o elemento possui dois estatutos e preenche duas funções: primeiro, ao receber a influência do campo, submete-se às suas forças; depois, o elemento intervém no campo a título criador e ativo, modificando suas linhas de força. Trata-se de uma correlação, e aqui o termo refere-se claramente ao caráter recíproco da interação elemento-todo, não se confundindo com a interação platônica ou aristotélica.

O modo de funcionamento de um campo magnético é tomado por Simondon (1989) como exemplo da idéia de correlação e reciprocidade. Se uma barra de ferro não-imantada é colocada no interior de um campo magnético, ela adquire características de imantação, em função do campo criado pelos imãs que já existiam e formavam o campo. Uma vez imantada, esta barra reage sobre a estrutura do campo e torna-se "cidadã da república do conjunto, como se ela própria fosse um imã criador desse campo" (SIMONDON, 1989, p. 44). A noção de campo eletromagnético possibilitou a apreensão de um tipo de campo dinâmico capaz de comportar a propagação de uma energia, oferecendo uma reciprocidade entre a função de totalidade e a função de elemento e um acoplamento dinâmico entre os elementos no interior do campo. O conceito de campo de forças tematizado pela física revelou "processos muito mais refinados de interação entre as partes por intermédio do todo onde intervêm mudanças seletivas" (SIMONDON, 1989, p. 46), influenciando decisivamente teorias e conceitos de outras áreas do saber, a exemplo da Psicologia da Forma - abordagem gestaltista dos fenômenos psicológicos - e, posteriormente, a Teoria de Campo de Kurt Lewin (1973). Brentano, filósofo do séc. XIX que conhecia profundamente as antigas noções de interação platônica e aristotélica é considerado o precursor da Teoria da Forma (gestaltis- 
mo), tendo inspirado inicialmente Ehrenfels, depois Kohler e Koffka, assim como todos os outros teóricos da forma que posteriormente utilizaram a noção de campo.

De acordo com a análise de Simondon (1989), a teoria gestaltista resultante da noção de campo recusa, ao mesmo tempo, a visão idealista (platônica) da forma e a visão empirista (aristotélica). Para os gestaltistas, a percepção, assim como a ação, é a apreensão e a realização de uma configuração do campo perceptivo, cujos elementos constitutivos estão em constante interação, tal como os imãs em um campo magnético. Além disso, o sujeito que percebe passa a constituir o campo perceptivo, ou seja, passa a ser realidade de um campo que se divide em dois subconjuntos: campo sujeito e campo objeto. A ação e a percepção seriam a descoberta de uma estrutura, de uma configuração comum ao campo exterior/fenomenal (campo objeto) e ao campo interior (campo sujeito), estrutura esta definida como o resultado de um estado de equilíbrio estável.

\section{Do equilíbrio estável à metaestabilidade: informação como intensidade}

É precisamente na idéia de estrutura resultante de um equilíbrio estável que Simondon situa a insuficiência da Teoria da Forma (Gestalt). O modelo de sistema em equilíbrio estável utilizado por esta teoria relaciona a operação de tomada de forma a um estado que é considerado por Deleuze, em Nietzsche e a filosofia, como um "estado terminal do devir", conforme nos lembram Prigogine e Stengers (1993, p. 199). Essa é a mesma crítica feita por Simondon à noção de boa forma, através da qual os gestaltistas buscam explicar a participação dos elementos na estrutura do todo. No gestaltismo a estrutura é a boa forma e esta possui duas características: a primeira é a capacidade de envolver o maior número possível de elementos e dar continuidade à tendência de cada sub-conjunto; a segunda, de ser a forma mais estável, a que não se deixa dissociar, a que se impõe, a mais provável.

Para Simondon, é incorreto relacionar boa forma a estabilidade ou probabilidade, pois em todos os domínios (físico, biológico, psíquico e social), "o estado mais provável é um estado de morte; é um estado degradado a partir do qual nenhuma transformação é possível sem intervenção de uma energia exterior ao sistema degradado" (SIMONDON, 1989, p. 49). Trata-se de um estado estável, porém desprovido de qualquer germe de devir. Não é uma boa forma, na medida em que não é significativa. Sendo assim, não é a tendência progressiva à estabilidade e homogeneidade no campo que produz formas pregnantes e significativas, mas a permanente atividade de irradiação e propagação em domínios novos.

Se podemos falar em equilíbrio ou permanência no interior da teoria da individuação, é somente no sentido de uma metaestabilidade, ferramenta conceitual que nos permite pensar um sistema que se mantém longe do equilíbrio estável, sem cair na instabilidade. Ao contrário do equilíbrio estável, a metaestabilidade aponta para um sistema/campo de natureza intensiva, portador de alto nível de energia potencial. Explicação que confere um estatuto de processualidade ao campo metaestável, ao mesmo tempo em que afirma a positividade do processo, ao invés de concebê-lo de maneira negativa, do ponto de vista do seu desaparecimento.

Prigogine e Stengers (1993), radicalizando a crítica ao equilíbrio estável, afirma que os processos ocorridos num sistema que tende ao equilíbrio acabam evoluindo para um estado onde estes processos se compensam mutuamente, anulando sua velocidade, e, ainda 
que haja relações recíprocas, o próprio funcionamento do sistema produz um desaparecimento gradativo das relações. A subordinação da idéia de processo a de estado resulta, para esses autores, em uma negação do processo enquanto tal:

O sistema físico, no sentido concreto que lhe deram a dinâmica e a termodinâmica, não conhece o tempo. Enquanto o sistema, isolado, fechado ou aberto, admite uma função potencial, a sua verdade está no seu estado, que terá, por direito, a mesma eternidade que o sistema (PRIGOGINE; STENGERS, 1993, p. 199).

Essa é também a conclusão a que chega Simondon, em sua teoria da individuação, dos processos de tomada de forma. Para ele a individuação não pôde ser adequadamente pensada porque a única forma de equilíbrio conhecida era o equilíbrio estável, que " [...] exclui o devir, pois corresponde ao mais baixo nível de energia potencial possível [...] e o sistema, tendo alcançado seu mais baixo nível energético, não pode se transformar novamente" (SIMONDON, 1989, p. 14). Ou seja, todas as teorias que partem da noção de equilíbrio estável não conseguem lidar de maneira processual com a questão da relação forma-matéria, todo-parte, pois subtraem das relações justamente a sua operatividade, ou seja, sua capacidade de acionar regimes e trocas significativas de informações que caracterizam os processos de individuação.

A Teoria da Informação, especialmente através do uso que é feito por Norbert Wiener ${ }^{5}$, concebe a informação a partir da física, mais especificamente, da termodinâmica line-

\footnotetext{
5 Embora Shannon (1916-2001) seja conhecido como "o pai da teoria da informação", foi Wiener (1948) quem associou a idéia de informação a de quantidade, afirmando ser tão importante a mensuração desta quanto a de energia ou de matéria. O fio de Cobre, por exemplo, passou a ser estudado e utilizado pela energia ou pela informação que era capaz de transmitir, e isso foi responsável por grande parte da revolução trazida pela informática.
}

ar (DUPUY, 1996). Emergindo no contexto da cibernética - teoria do controle e comunicação da máquina e do animal - não é de surpreender que essa teoria, segundo Simondon (1989), ofereça uma explicação plausível para certos sistemas de aprendizagem, mas contenha graves limitações em relação ao tema nos domínios da psicologia e da sociologia. Partindo da premissa de que quanto "mais a correlação entre emissor e receptor é estreita, menor é a quantidade de informação" (SIMONDON, 1989, p. 51), em uma aprendizagem realizada com êxito (por exemplo, o domínio de uma máquina por um operador que nela trabalha), a melhor forma corresponde justamente à menor quantidade de informação e, como conseqüência, resulta de um estado em que a correlação ou a reciprocidade tende a se extinguir.

Eis o paradoxo a ser solucionado a fim de que a noção de informação possa ser utilizada, por exemplo, em psicologia e em sociologia: encontrar algo que permita relacionar uma melhor forma ao mais alto grau de informação. Por considerar que a idéia de qualidade remetia ainda a uma propriedade absoluta do ser, Simondon opta por tomar emprestado à energética o termo intensidade de informação: a intensidade é sempre relacional, ou seja, ela é significativa para o sistema que recebe a informação (SIMONDON, 1964). A intensidade da informação diz respeito a uma diferença de potencial, podendo também ser denominada tensão de informação. Isso permite explicar os processos de tomada de forma sem recorrer à idéia de boa forma, e tampouco a uma grandeza de informação, mas a partir de uma operação decorrente da intensidade de informação, ou, das relações existentes em um campo. No lugar de uma boa, ou melhor, Forma, uma forma intensiva, tensionada pela existência de ordens de grandeza incompatíveis, ou ainda, aquela que "contém um campo 
de forma elevado, isto é, uma boa distinção, um bom isolamento entre os dois ou a pluralidade de termos que a constituem e, no entanto, entre eles, um campo intensivo, um poder de produzir efeitos energéticos se algo é introduzido nele" (SIMONDON, 1989, p. 52).

No artigo Gilbert Simondon, o indivíduo e sua gênese fisico-biológica, Deleuze, ao caracterizar o ser pré-individual, nos fornece importantes pistas para o entendimento do conceito de informação na teoria da individuação: "Singular sem ser individual, eis o estado do ser pré-individual. Ele é diferença, disparidade, disparação[...] disparidade, como primeiro momento do ser, como momento singular ..." (DELEUZE, 2003, p. 121). Em seguida desenvolve toda uma argumentação para mostrar como a individuação é um processo de resolução desse primeiro estado problemático ${ }^{6}$ do ser, resolução que se dá através de duas formas complementares: como ressonância interna, entendida como um grau mais primitivo de "comunicação entre realidades de ordem diferente"; e, como informação, entendida como aquilo que "estabelece uma comunicação entre dois níveis díspares, um definido por uma forma já contida no receptor, o outro definido pelo sinal trazido do exterior"(DELEUZE, 2003, p. 122). A Informação comparece então como resolução de uma disparidade, ou, de uma problemática pré-individual.

Simondon contrapõe à Forma estável a idéia de uma forma metaestável e intensiva. Tensão, intensidade e potencial de informação ou de forma. Qualquer que seja o termo utilizado nesse contexto conceitual, os significados remetem a uma dimensão energética que reúne aspectos ou dinamismos habitualmente

6 Deleuze destaca ainda que o conceito de"problemático" em Simondon deixa de ter um sentido negativo, subjetivo e indeterminado para adquirir, um sentido objetivo, designando um momento do ser, o primeiro momento pré-individual. distintos e incompatíveis7, cuja concentração é levada a um limite disruptivo. O campo intensivo de informação é considerado também como uma rede, no sentido em que opera uma conexão significativa do um e do múltiplo, uma correlação entre múltiplos e diferentes termos.

A tensão de informação é a propriedade que permite ao sistema, entendido como rede, estruturar um domínio e propagar-se através dele, ordenando-o. Se retomamos a noção de pregnância da forma, diremos que esta é dada justamente pelo alto nível de tensão, pela capacidade de atravessar e estruturar domínios cada vez mais variados e heterogêneos, e não pela estabilidade. Resulta que, para que haja uma tomada de forma, é preciso que duas condições sejam atendidas conjuntamente: uma tensão de informação produzida por um germe estrutural e informativo e uma energia contida na matéria informável. Isso define a operação de tomada de forma como uma operação de modulação, ${ }^{8}$ que significa a ação do germe estrutural/informativo sobre um domínio estruturável/metaestável e sua expansão no interior deste domínio. Esta operação desenrola-se em "uma micro-estrutura que avança progressivamente através do domínio que toma forma, constituindo o limite movente entre a parte informada (estável) e a parte não informada ainda (metaestável) do domínio" (SIMONDON, 1989, p. 55).

A relação forma-matéria numa teoria energética traduz-se então por uma relação

7 Isto não significa o estabelecimento de uma equivalência entre forma e informação, quando estes são tomados separadamente. Para Simondon a forma, entendida como regularidade espacial e temporal, não é uma informação, mas sim uma condição da informação, esta entendida como variabilidade das formas (SIMONDON, 1989).

8 Em Física, a modulação define um tipo de operação de interação física, que se realiza em um relais amplificador, em número infinito de estados. Trata-se de uma operação pela qual um sinal de fraca energia atualiza com um certo número de graus possíveis a energia potencial de um certo campo. 
transdutiva ${ }^{9}$ e progressiva da dupla estruturante-estruturado, através de um limite ativo que faz passar a informação. Mas é a energia metaestável que permite à estrutura avançar, já que os potenciais de propagação residem na própria matéria, tendo o limite como um relais amplificador (SIMONDON, 1989, p. 33). Considerando que em tal modelo a informação avança de forma irreversível, o limite entre eles se desloca de maneira contínua e igualmente irreverssível, o que é estabelecido em cada operação transdutiva funciona como germe estrutural da próxima operação, isso significa dizer, por um lado, que o próprio limite atua como modulador, e, por outro, que há "mudança local progressiva do estatuto ontológico do meio" (SIMONDON, 1989, p. 61). O meio externo pode passar a compor a interioridade de um sistema, fazendo emergir simultaneamente outras exterioridades, outros meios associados ${ }^{10}$.

Encontram-se reunidas nessa operação de transdução ou modulação a assimetria da dupla hilemórfica (forma e matéria), cuja matéria apresenta tendência, e o poder arquetípico da forma platônica, que preexiste à tomada de forma. Conforme assinala Fagot-Largeault "...em Simondon, quando duas teses estão em conflito, longe de opô-las dialeticamente,

\footnotetext{
9 Simondon oferece várias definições de transdução, todas relacionadas entre si e muito próximas do que é nomeado como operação de modulação: "uma operação física, biológica, mental, social, pela qual uma atividade se propaga gradativamente no interior de um domínio..." (SIMONDON, 2003, p. 112), "... a transdução é aparição correlativa de dimensões e de estruturas em um ser em estado de tensão pré-individual, isto é, em um ser que é mais que unidade e mais que identidade, e que ainda não se defasou em relação a si próprio em múltiplas dimensões" (SIMONDON, 2003, p. 112), "A transdução corresponde a essa existência de relações que nascem quando o ser pré-individual se individua; ela exprime a individuação e permite pensá-la, logo, é uma noção simultaneamente metafísica e lógica; aplica-se à ontogênese e é a própria ontogênese" (SIMONDON, 2003, p. 113).
}

10 O conceito de meio associado, no pensamento de Simondom, remete a ideia que em todo processo de individuação o meio é criado simultaneamente ao indivíduo. deve-se tentar reuni-las."(FAGOT-LARGEAULT, 1994, p.38): "...tirar sentido do conflito" (FAGOT-LARGEAULT, 1994, p.38). Esse é, a nosso ver, um dos traços centrais da perspectiva de Simondon: explicar os processos de tomada de forma não simplesmente opondo-se à teoria arquetípica platônica e à teoria hilemórfica aristotélica, mas tomando partido de agenciamentos conceituais que revelam uma potência de propagação e fecundação em domínios heterogêneos, desde as formas físicas até os fenômenos grupais e sociais.

Quando aplicada ao psíquico, essa teoria permite analisar, por exemplo, a gênese do pensamento, identificando a experiência como um domínio de metaestabilidade. A reduplicação das experiências é considerada uma atividade que faz passar o conteúdo mental a um estado supersaturado. Vejamos: "A experiência relativa a um mesmo objeto reúne e superpõe aspectos parcialmente contraditórios, produzindo um estado metaestável do saber relativo ao objeto" (SIMONDON, 1964, p. 60). No que se refere ao social, "as variações aleatórias nas amostras do domínio social, não permitem uma verdadeira previsibilidade nem uma verdadeira explicação, pois quanto mais extensas, mais heterogêneas são as amostras" (SIMONDON, 1964, p. 62). Sendo assim, o que há de mais importante a explicar são justamente as configurações decorrentes dos estados metaestáveis, ricos em potenciais, como o estado pré-revolucionário, "onde um acontecimento está prestes a se produzir, onde uma estrutura está prestes a jorrar; basta que o germe estrutural apareça, e às vezes, mesmo 0 acaso pode produzir o equivalente do germe estrutural"(SIMONDON, 1964, p. 63). Sociedades e grupos se transformam em função das condições de metaestabilidade, ou seja, por uma disparidade interna: os grupos, assim como os indivíduos (psíquicos) e as moléculas, 
tornam-se incompatíveis com relação a si próprios. Há uma diferenciação causada por uma supersaturação energética.

O autor busca resolver os problemas relativos à interação forma-matéria, todo-parte, individual-coletivo, através de agenciamentos conceituais transdutivos ${ }^{11}$ entre noções oriundas de teorias tradicionalmente opostas e noções da energética. Assim, na teoria da individuação o germe arquetípico deixa de ser uma forma superior e imutável e passa a ser germe informativo. Da relação hilemórfica, Simondon retém a idéia de uma matéria que apresenta tendência, mas esta deixa de ser natural para ser efeito de um regime de metaestabilidade.. A noção de forma perde então o estatuto transcendente do esquema arquetípico e passa a ser concebida como forma intensiva, capaz de estruturar a matéria, quando esta se encontra em estado metaestável.

Em Diferença e Repetição, Deleuze propõe uma nova concepção do transcendental para falar do processo de individuação dos seres. Embora considere que, com o conceito de transcendental, Kant tenha buscado reverter a imagem do pensamento e renunciar ao Eu substancial, Deleuze (1988) argumenta que este filósofo não abre mão dos pressupostos implícitos da representação, o que fica evidenciado pela sua pressa em "decalcar" as estruturas ditas transcendentais sobre os atos empíricos de uma consciência psicológica. Em sintonia com Simondon, afirma a existência

\footnotetext{
11 Esse agenciamento exigiu uma distinção conceitual entre campo e domínio. Embora o termo campo seja utilizado, em alguns momentos, como sinônimo de domínio, ao introduzir sua concepção energética do psiquismo e do social, Simondon reserva o conceito de campo para definir aquilo que existe no interior de um arquétipo, ou seja, as estruturas quase paradoxais que servem de germe para o indivíduo e que podem ser reunidas sob os termos tensão de informação ou intensidade de informação (ou de forma). Resulta disso o conceito de campo de intensidades. A noção de domínio refere-se ao conjunto da realidade que pode tomar forma, ser individuada, pela operação transdutiva, confundindo-se com a matéria metaestável (SIMONDON, 1989, p. 64)
}

de um campo transcendental impessoal e préindividual que não se confunde nem com a forma pessoal de um Eu kantiano, nem com a forma consciência, mesmo que esta seja descrita em termos de intencionalidades e retenções puras. (DELEUZE, 1988). Com isso, estende à filosofia kantiana a crítica realizada por Simondon à metafísica substancialista. O que há de comum entre a metafísica e a filosofia transcendental kantiana é, segundo Deleuze:

Esta alternativa que elas nos impõem: ou um fundo indiferenciado, sem fundo, não-ser informe, abismo sem diferenças e sem propriedades - ou então um Ser soberanamente individuado, uma forma fortemente personalizada. Fora deste Ser ou desta Forma, não tereis senão o caos... Em outros termos, a metafísica e a filosofia transcendental se entendem a fim de não conceberem singularidades determináveis a não ser já aprisionadas em um Ego individual (Moi) supremo ou um Eu pessoal (Je) superior (DELEUZE, 1974, p. 109).

Como assinala Agamben (2000), trata-se para Deleuze de "alcançar uma zona-pré-individual e absolutamente impessoal, além (ou aquém) de toda idéia de consciência" (AGAMBEN, 2000, p. 174). O resultado é um empirismo transcendental: separado de toda idéia de consciência, o transcendental deleuziano se apresenta como uma experiência sem consciência nem sujeito, invertendo a fórmula do transcendental kantiano que remetia a uma consciência pura sem experiência alguma. Citamos Deleuze: "Quando se abre o mundo pululante das singularidades anônimas e nômades, impessoais, pré-individuais, pisamos, afinal, o campo do transcendental" (DELEUZE, 1974, p. 106).

Mireille Buydens (1990) enfatiza a decisiva influência do pensamento de Simondon na caracterização do campo transcendental deleuziano - especialmente quanto ao seu caráter 
pré-individual - e os desdobramentos em direção a uma concepção de forma transcendental. Buydens (1990) estabelece uma equivalência entre indivíduo e forma ${ }^{12}$, pois considera que esta é justamente o que "institui o indivíduo como tal, traçando o contorno que o distingue do mundo e o especifica" (BUYDENS, 1990, p. 17). Tal como o indivíduo, a forma não existe a priori, é segunda e relativa. Antes da emergência da forma/indivíduo, existem singularidades pré-individuais, que se definem por sua natureza intensiva e metaestável: eis a afirmativa que reúne as explicações deleuziana e simondoneana para a questão da gênese do seres individuados. Como assinala Buydens (1990), Deleuze afirma que a metaestabilidade é a própria virtualidade.

A autora considera que o campo transcendental, em Deleuze, pode ser caracterizado de duas maneiras: de maneira extrínseca e de maneira intrínseca. Extrínseca, na medida em que pode ser dito um "extra-ser", que subsiste na superfície das coisas como pura virtualidade e que se atualiza na esfera da efetividade, sem que isso, entretanto, jamais o esgote totalmente. O mundo é pensado aqui a partir de um potencial que Ihe ultrapassa e excede-Ihe, sem, no entanto, existir fora dele. Do ponto de vista intrínseco, o campo transcendental deleuziano é constituído de singularidades nômades, impessoais e pré-individuais. Definido como campo de potenciais metaestáveis, o préindividual expressa a idéia de intensidade na teoria da individuação, apropriada por Deleuze para definir o campo transcendental como campo de intensidade, implicando sempre uma diferença, pois a energia em questão é uma energia potencial, na acepção que lhe

12 Buydens (1990) afirma que os conceitos de multiplicidade, em Deleuze e Guatarri (1995) e o de dobra, apresentado por Deleuze na obra Foucault (DELEUZE, 2005) são fundamentais na elucidação do estatuto da forma pois ambos possuem um caráter secundário com relação a uma instância precedente e pré-formal. confere a física. Conforme esclarece Simondon, "a capacidade para uma energia de ser potencial está estritamente ligada à presença de uma relação de heterogeneidade, de dissimetria com relação a outro suporte energético" (SIMONDON, 1964, p.76).

De natureza heterogênea e relacional, a realidade potencial, préindividual e metaestável, apresenta-se pois como um campo problemático, cuja resolução se dá, tanto para Simondon quanto para Deleuze, pela informação - entendido como processo relacional e significativo - fazendo-a coincidir com a própria operação de tomada de forma, a individuação

A idéia de um ser pré-individual que se atualiza em formas individuadas, resulta na destituição do indivíduo como dado primeiro e único - ponto central da teoria da individuação. Além de não esgotar os potenciais da realidade pré-individual, a individuação faz aparecer não somente o indivíduo, mas a dupla indivíduo-meio. O indivíduo é então, duplamente relativo: por um lado não é o ser completo, na superfície subsiste um pré-individual; por outro, é ontologicamente secundário, resulta de um estado do ser no qual ele não existia nem como princípio de individuação ${ }^{13}$.

Por fim, considerando a dimensão psíquica e coletiva da individuação, nesse contexto de pensamento simondoneano-deleuziano, podemos dizer que, como toda forma, a forma-subjetividade resulta de individuações, de conjunção de forças e contingências. O que aponta para a possibilidade de individuações que produzam não as formas atuais, mas outras formas, nem Homens nem Sujeitos: individuações ou individualidades impessoais.

13 Isso não significa que o indivíduo seja cronologicamente secundário. A afirmação de um estado do ser não-fasado e de sua posterior defasagem em indivíduo e meio, não decorre de uma lógica de sucessão temporal, da passagem de um ser pelo tempo. Ao contrário, a individuação é a própria temporalização e o ato de defasar é uma operação de cisão temporal (PELBART, 1998). 


\section{Referências}

AGAMBEN, G. A imanência absoluta. In: ALLIEZ E. (Org.). Gilles Deleuze: uma vida filosófica. São Paulo: Ed. $34,2000$.

BUYDENS, M. Sahara. L'Esthétique de Gilles Deleuze. Paris: Vrin, 1990.

DELEUZE, G. Diferença e repetição. Rio de Janeiro: Graal, 1988.

DELEUZE, G. Nietzsche e a filosofia. Rio de Janeiro: Ed. Rio, 1976.

DELEUZE, G. Foucault. São Paulo: Brasiliense, 2005.

DELEUZE, G. Lógica do sentido. São Paulo: Perspectiva/ Ed. da USP, 1974.

DELEUZE, G. Gilbert Simondon, o indivíduo e sua gênese físico-biológica. In: PELBART, P.; COSTA, R. (Org.). O reencantamento do concreto. Cadernos de subjetividade. São Paulo: Hucitec. 2003.

DEleuZE, G; GuATTARI, F. Mil Platôs: capitalismo e esquizofrenia. Vol. 1. Rio de Janeiro: Ed. $34,1995$. DUPUY, J-P. Nas origens das ciências cognitivas. São Paulo: UNESP, 1996.

ESCÓSSIA, L. Relação homem-técnica como individuação do coletivo. Aracaju: Editora UFSE/FOT, 1999.

ESCÓSSIA, L. A Invenção Técnica: transindividualidade e agenciamento coletivo. Informática na educação: teoria \& prática. Porto Alegre, v.13, n.2, jul./dez. 2010.

ESCÓSSIA, L. Por uma ética da metaestabilidade na relação homem-técnica. In: PELBART, P.; COSTA, R. (Org.). O reencantamento do concreto. Cadernos de subjetividade. São Paulo: Hucitec. 2003.

FAGOT-LARGEAULT, A. L'individuation en biologie. In: CHÂTELET, G. (Org.). Gilbert Simondon; une pensée de I'individuation et de la technique. Paris: Aubier, 1994.

LEWIN, Kurt . Princípios de Psicologia Topológica. São Paulo: Cultrix-Editora da USP, 1973.

PELBART, P. O tempo não-reconciliado. 1. ed. São Paulo: Perspectiva, 1998.

PRIGOGINE, I; STENGERS, I. Sistema. In: Enciclopédia Einaldi, v. 26. Lisboa: Imprensa Nacional-Casa da Moeda, 1993.

SERRES, M. Filosofia Mestiça. Rio de Janeiro: Francisco Alves, 1993.

SHANNON, C. E. A mathematical theory of communication. Bell System Technical Journal, vol. 27, pp. 379423 and 623-656, July and October, 1948. 
SIMONDON, G. L'individu et sa genèse psysico-biologique. Paris: Presses Universitaires de France, 1964.

SIMONDON, G. L'individuation psychique et colletive. Paris: Aubier, 1989.

SIMONDON, G. A Gênese do indivíduo. In: PELBART, P.; COSTA, R. (Org.). O reencantamento do concreto. Cadernos de subjetividade. São Paulo: Hucitec. 2003.

WIENER, N. Cybernetics: or the control and communication in the animal and the machine. Massachusetts Institute of Technology, 1948.

Recebido em: 13 de outubro de 2011

Aprovado para publicação em: 28 de novembro de 2011

\section{Liliana da Escóssia}

Professora do Departamento de Psicologia e do Mestrado em Psicologia Social e Política da Universidade Federal de Sergipe - Aracajú/SE, Brasil. E-mail: liliana.em@infonet.com.br 